Supporting Information for:

\title{
Ligand-Induced G-Quadruplex Polymorphism: A DNA Nanodevice for Label-Free Aptasensor Platforms
}

Prashant S. Deore, Micaela D. Gray, Andrew J. Chung and Richard A. Manderville*

Table of Contents:

1. Figure S1. Fluorescence displacement of NMM by BtC from H-Telo22.

2. Figure S2. CD displacement of $B t C / 4 Q$ I from $\mathrm{H}$-Telo22 by NMM.

3. Figure S3. Fluorescence binding titrations of $\mathrm{H}-\mathrm{Telo} 22$ with $\mathrm{BtC}$ and $4 \mathrm{QI}$.

4. Figures S4. CD and Fluorescence displacement of $4 \mathrm{QI}$ by BtC from H-Telo22.

5. Figures S5. Fluorescence spectra of ligands: Free and bound to H-Telo22.

6. Figure S6. Binding isotherms for the dyes binding to OTABA.

7. Figure S7. LoD and LoQ determination for OTA binding.

8. Figure S8. Emission comparison of ThT, $4 \mathrm{QI}$ and BtC bound to OTABA.

9. Figure S9. Selectivity and anti-interference response of BtC-OTABA system.

10. Table S1. Recovery experiments from spiked OTA in red wine samples.

11. Figures S10-S12. ${ }^{1} \mathrm{H}$ NMR, ${ }^{13} \mathrm{C}$-jmod and HRMS spectra of $4 \mathrm{QI}$. 


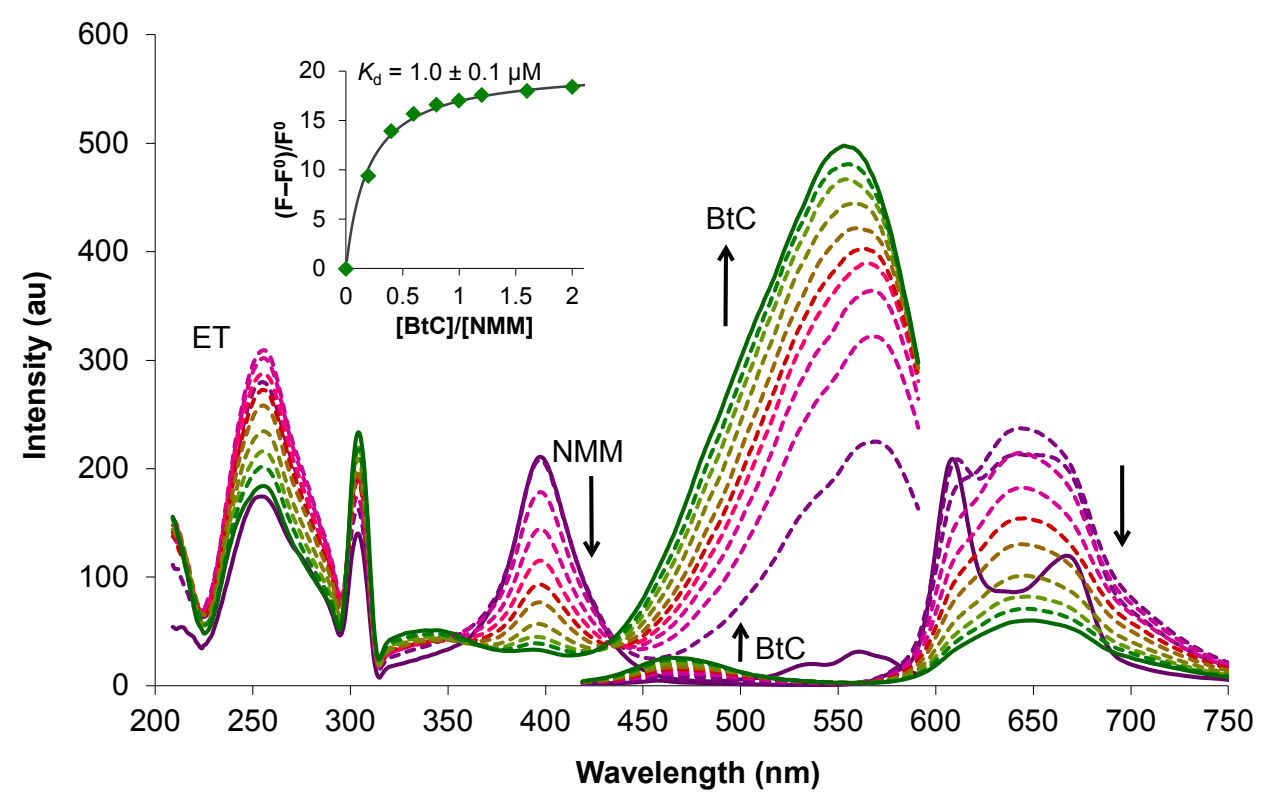

Figure S1. Fluorescence titration of H-Telo22 $(1 \mu \mathrm{M})$ with $\mathrm{BtC}(0-10 \mu \mathrm{M})$ showing displacement of NMM $(5 \mu \mathrm{M})$ in $50 \mathrm{mM}$ potassium phosphate buffer containing $100 \mathrm{mM} \mathrm{KCl}$ at $25{ }^{\circ} \mathrm{C}$. Inset: Binding isotherm obtained by plotting fluorescence excitation at $580 \mathrm{~nm}\left(\lambda_{\mathrm{Em}}=\right.$ $609 \mathrm{~nm})$ and $K_{\mathrm{d}}=1.0 \pm 0.1 \mu \mathrm{M}$ measured using sigma plot software - simple ligand binding model.
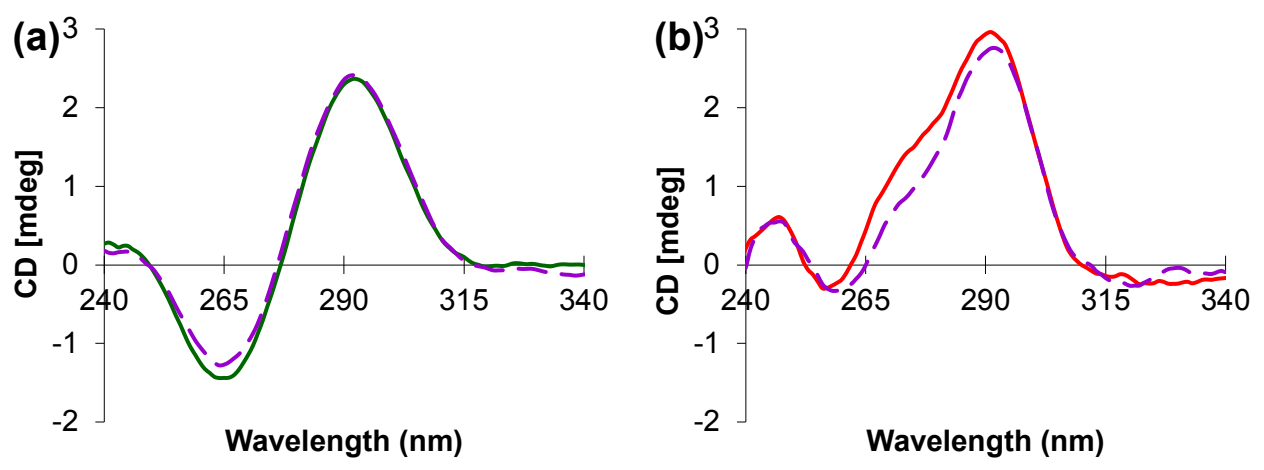

Figure S2. CD spectra of H-Telo22 $(3 \mu \mathrm{M})$ with (a) BtC $(15 \mu \mathrm{M}$, solid green trace) and (b) 4QI (15 $\mu \mathrm{M}$, solid red trace) ligands and their corresponding displacement (dashed purple traces) by $\mathrm{NMM}$ ligand $(30 \mu \mathrm{M})$ in $50 \mathrm{mM}$ potassium phosphate buffer containing $100 \mathrm{mM} \mathrm{KCl}$ at 15 ${ }^{\circ} \mathrm{C}$. 

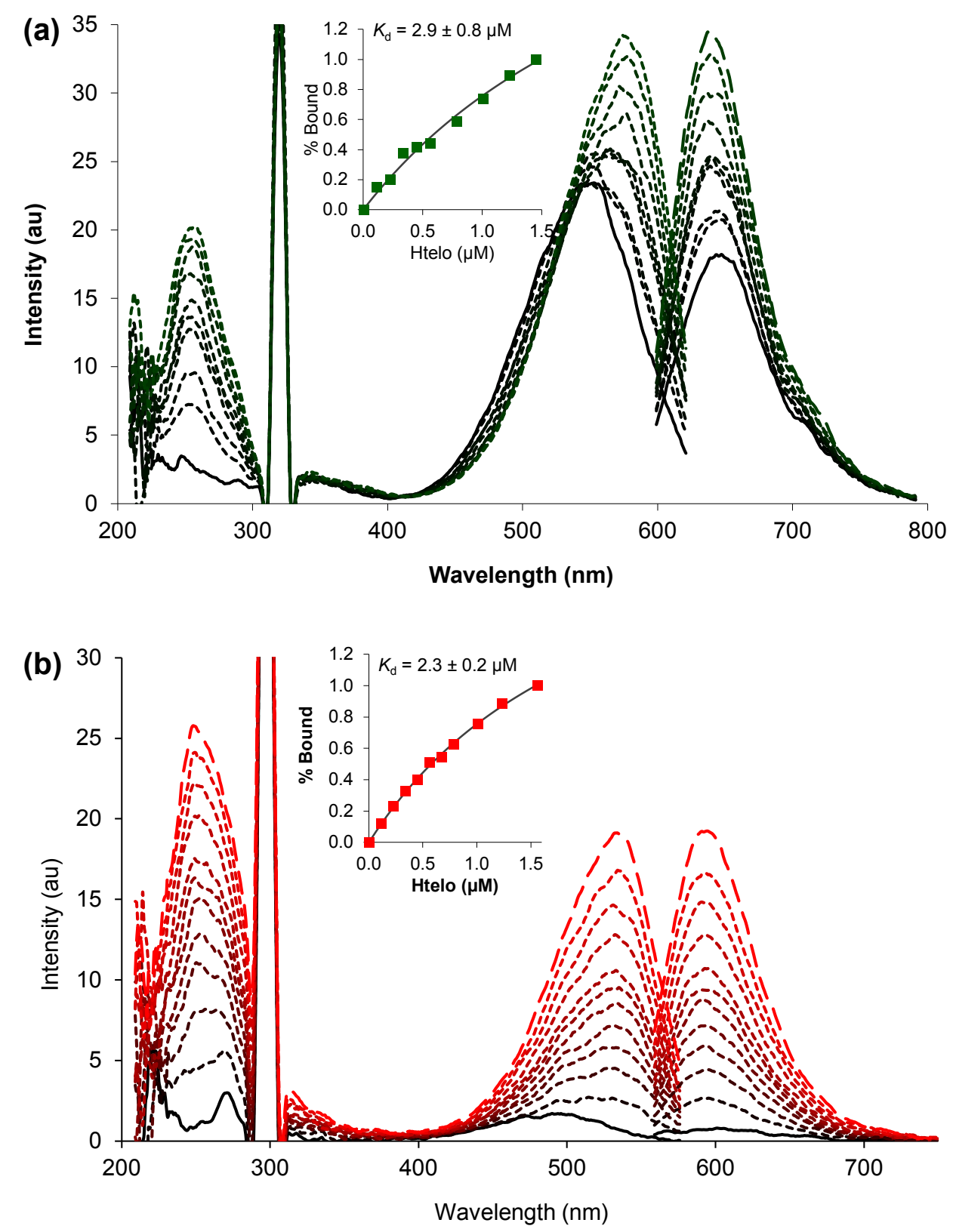

Figure S3. Fluorescence titrations of (a) BtC $(0.5 \mu \mathrm{M}$, dotted green traces) and (b) 4QI (0.5 $\mu \mathrm{M}$, dotted red traces) with $\mathrm{H}$-Telo22 $(0-1.5 \mu \mathrm{M})$. Inset: Binding isotherm obtained by plotting corresponding fluorescence emission at $645 \mathrm{~nm}\left(\lambda_{\mathrm{Ex}}=580 \mathrm{~nm}\right)$ and $595 \mathrm{~nm}\left(\lambda_{\mathrm{Ex}}=533 \mathrm{~nm}\right)$ to provide binding constants as $K_{d}=2.9 \pm 0.8 \mu \mathrm{M}$ and $K_{d}=2.8 \pm 0.2 \mu \mathrm{M}$ for BtC and $4 \mathrm{QI}$ binding to $\mathrm{H}$-Telo22 in $50 \mathrm{mM}$ Tris buffer containing $50 \mathrm{mM} \mathrm{NaCl}$ at $25^{\circ} \mathrm{C}$. 

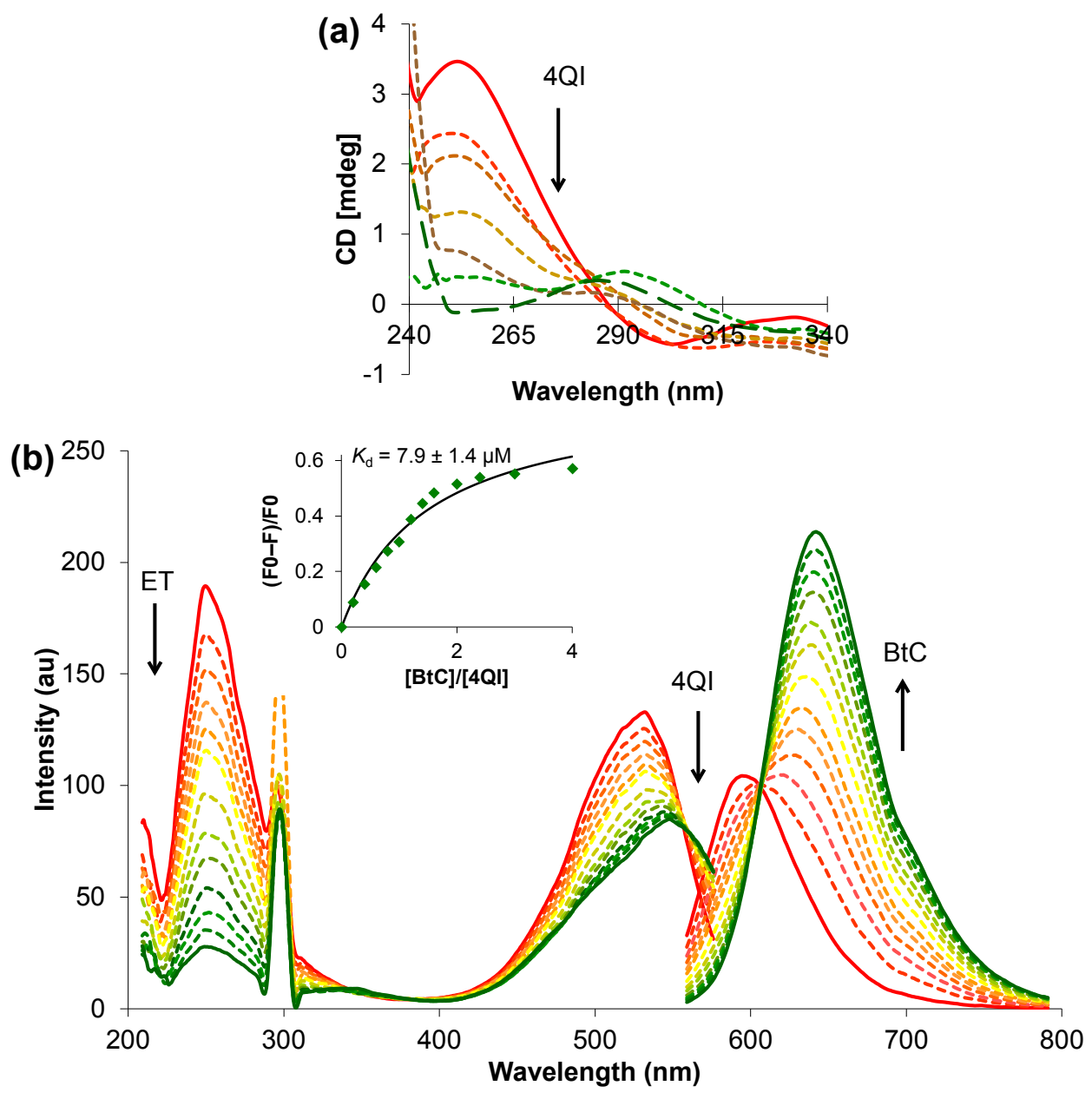

Figure S4. Respective (a) CD and (b) fluorescence titrations demonstrating changes in GQ topology of $\mathrm{H}$-Telo22 $(3$ and $1 \mu \mathrm{M})$ with displacement of (a) 4QI (30 and $5 \mu \mathrm{M})$ by BtC $(240$ and $20 \mu \mathrm{M}$ ) ligand in $50 \mathrm{mM}$ Tris buffer containing $50 \mathrm{mM} \mathrm{NaCl}$ at 15 and $25^{\circ} \mathrm{C}$. Fluorescence emission was monitored for $4 \mathrm{Q}$ at $595 \mathrm{~nm}\left(\lambda_{\mathrm{Ex}}=533 \mathrm{~nm}\right)$ and binding isotherm was plotted against the ratio of $\mathrm{BtC}$ to $4 \mathrm{Q}$ lo obtain $K_{\mathrm{d}}=7.9 \pm 1.4 \mu \mathrm{M}$ using sigma plot software - simple ligand binding model. 

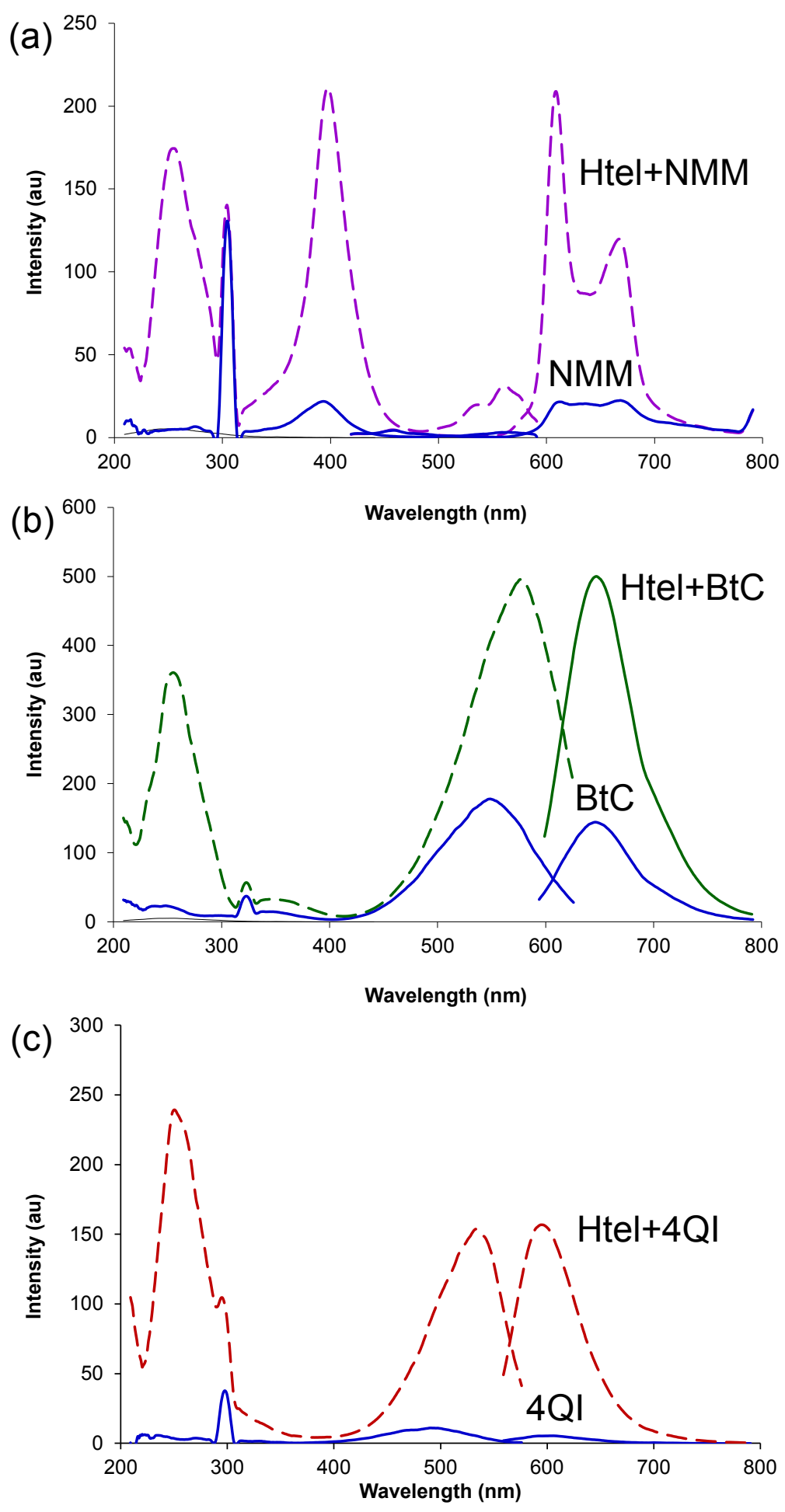

Figure S5. Fluorescence spectra for $5 \mu \mathrm{M}$ of (a) NMM (purple), (b) BtC (green) and (c) 4QI (red) fluorescent ligands in the absence (solid blue lines) and in presence of H-Telo22 (1 $\mu \mathrm{M}$, dashed lines), acquired in $50 \mathrm{mM}$ potassium phosphate buffer containing $100 \mathrm{mM} \mathrm{KCl}$ at 25 ${ }^{\circ} \mathrm{C}$. 

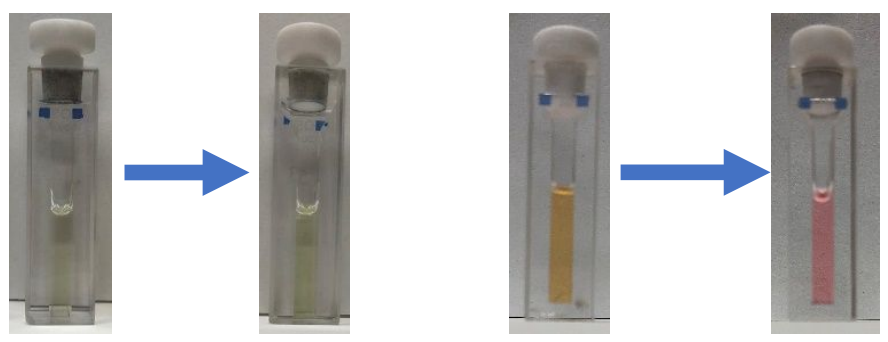

(a) ThT

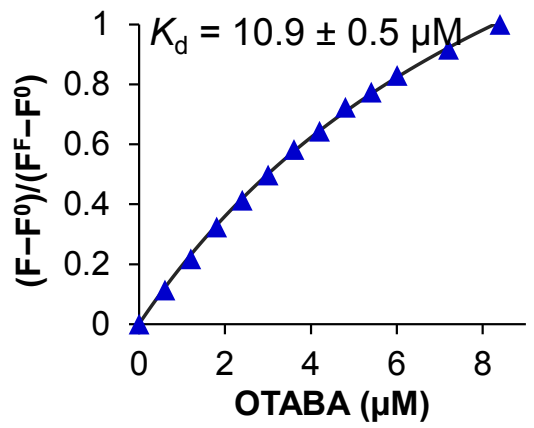

(b) $4 \mathrm{QI}$

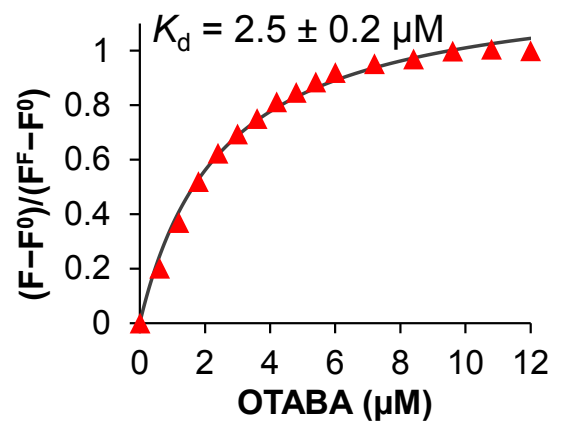

(c) $\mathrm{BtC}$

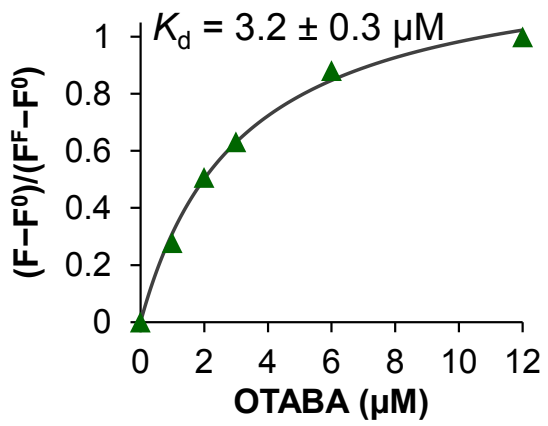

Figure S6. Binding isotherm obtained and $K_{d}$ value determined using sigma plot software simple ligand binding model for OTABA $(0-12 \mu \mathrm{M})$ binding to ThT $(6 \mu \mathrm{M}$, blue trace), 4QI (6 $\mu \mathrm{M}$, red trace) and BtC (6 $\mu \mathrm{M}$, green trace). Fluorescence titrations were performed in OTA binding buffer $(\mathrm{pH}=8)$ and at $25^{\circ} \mathrm{C}$. Inset: Color of $10 \mu \mathrm{M}$ of ThT, 4QI and BtC probes in absence and in presence of $5 \mu \mathrm{M}$ of OTABA, respectively.
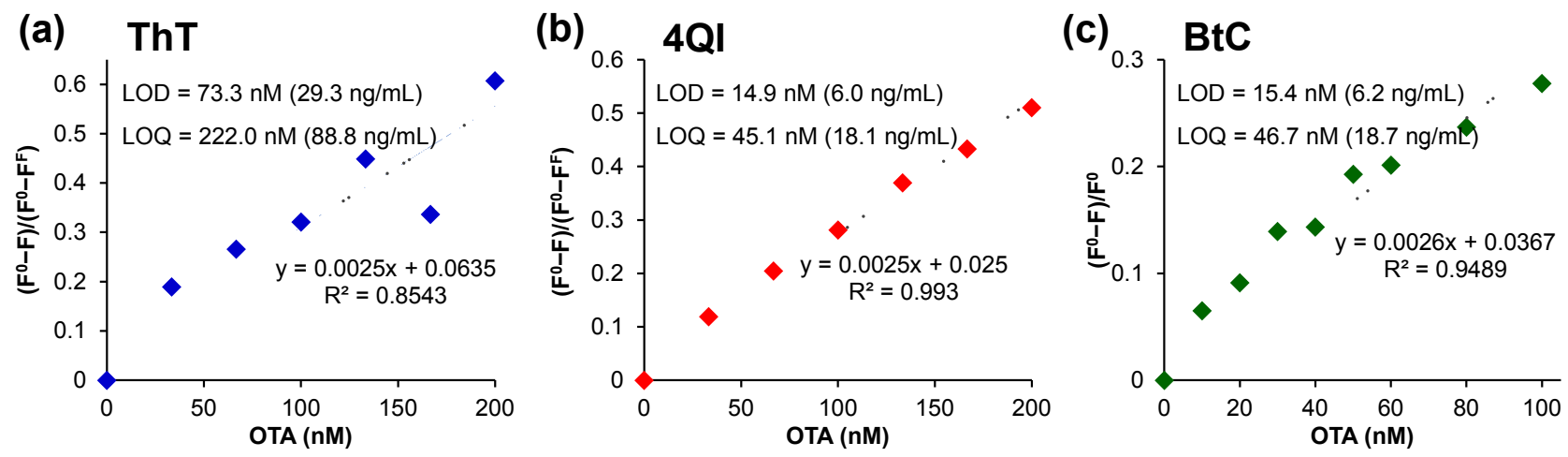

Figure S7. Determination of Limits of Detection (LoD) and quantification (LoQ) for OTA binding to OTABA and displacing ThT (blue markers), 4QI (red markers) and BtC (green markers). 


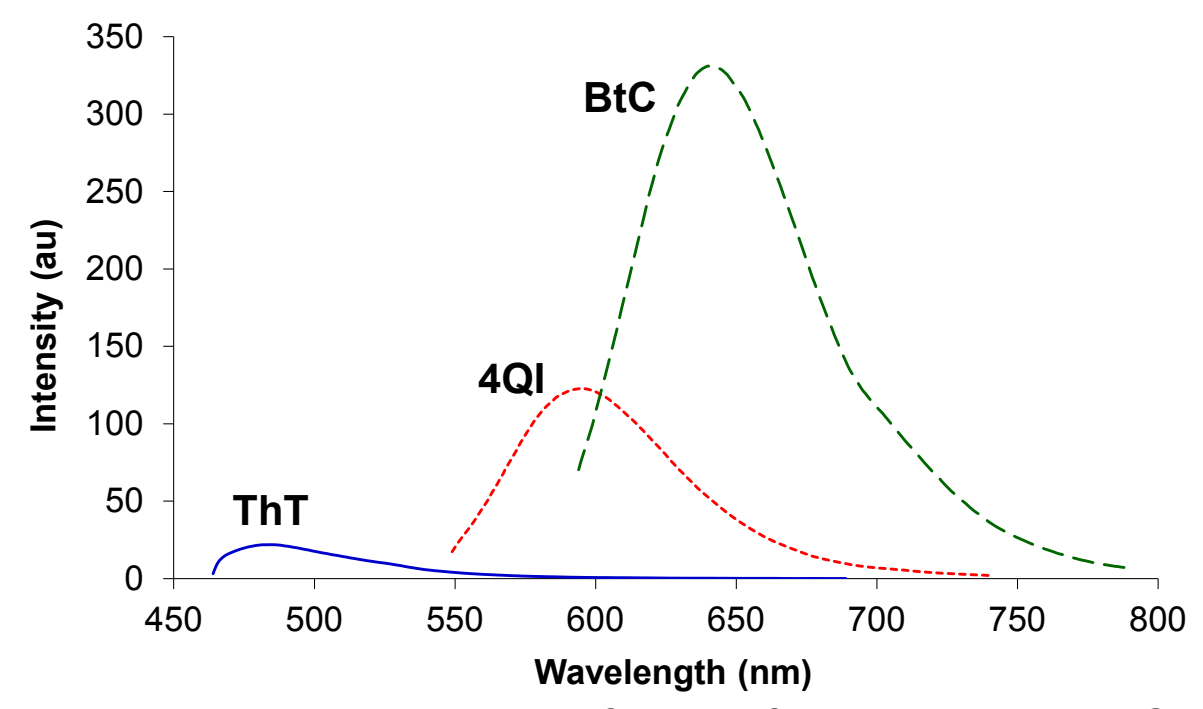

Figure S8. Fluorescence emission spectra of $1 \mu \mathrm{M}$ of ThT (solid blue), 4QI (dotted red) and $\mathrm{BtC}$ (dashed green) in the presence of $0.5 \mu \mathrm{M}$ OTABA recorded at $25^{\circ} \mathrm{C}$ in the OTA binding buffer.

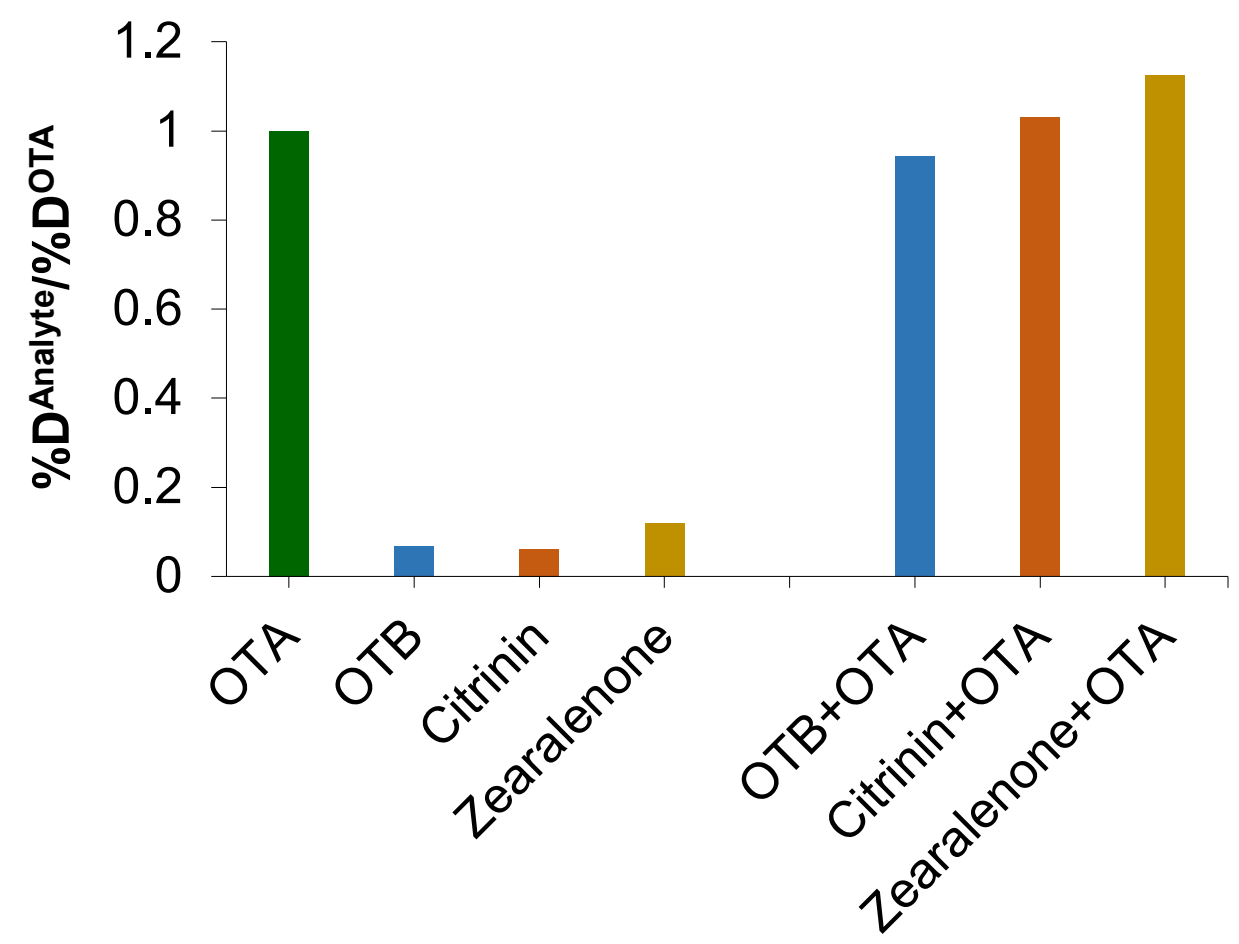

Figure S9. Selectivity and anti-interference response of BtC-OTABA system towards OTA. Fluorescence response BtC-OTABA probe $(1: 0.5 \mu \mathrm{M})$ in terms of $\%$ drop for presence of individual mycotoxins $(4 \mu \mathrm{M})$ and also in co-existence with OTA $(4 \mu \mathrm{M}) . \% \mathrm{D}^{\text {Analyte }}$ is the $\%$ intensity drop measured for different analytes, individually or in co-existence of OTA, as indicated. 
Table S1. Results of recovery experiments from the analysis of spiked red wine samples using OTABA-BtC system.

$\begin{array}{cccc}\begin{array}{c}\text { spiked OTA } \\ (\mu \mathrm{M})\end{array} & \begin{array}{c}\text { recovered OTA } \\ (\mu \mathrm{M})\end{array} & \text { \% recovery } & \text { RSD }(\%) \\ 0.13 & 0.15 & 115 \pm 2.3 & 1.06 \\ 0.27 & 0.24 & 89 \pm 3.8 & 1.83 \\ 0.53 & 0.49 & 93 \pm 3.9 & 2.12 \\ & 0.95 & 95 \pm 4.3 & 2.50\end{array}$

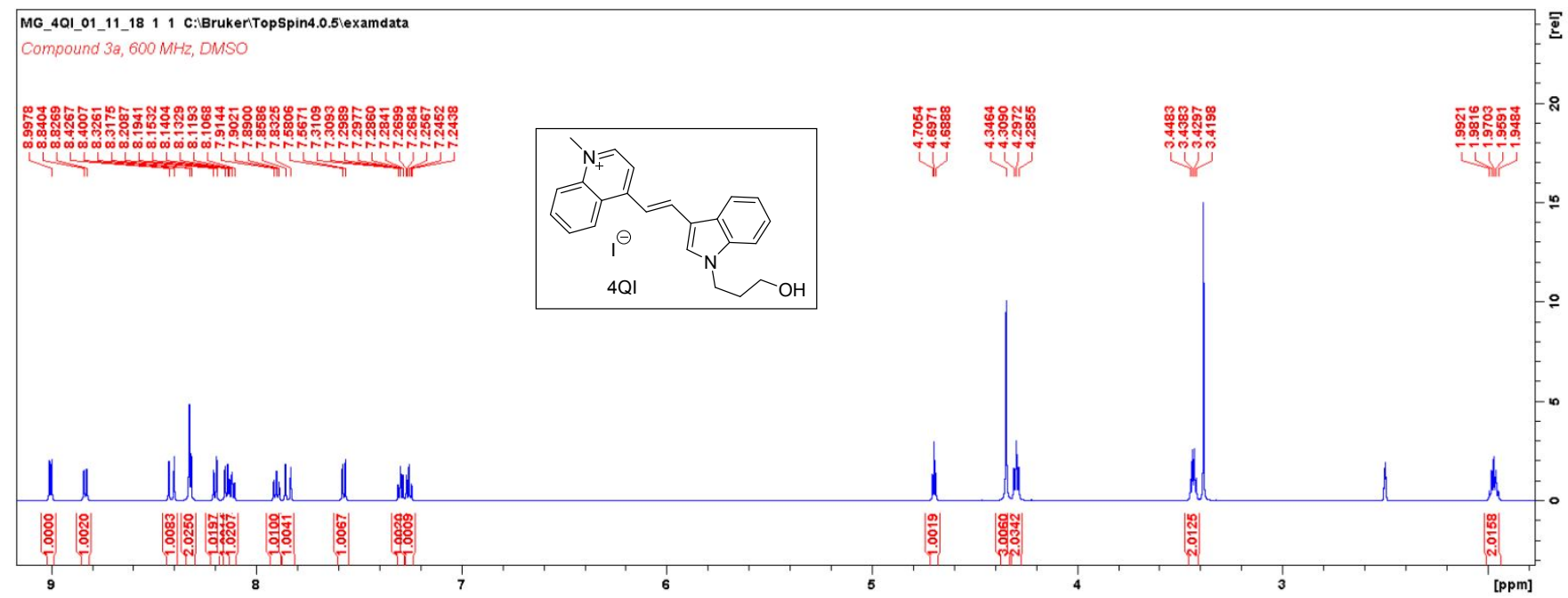

Figure S10. ${ }^{1} \mathrm{H}$ NMR spectra of 4 QI.

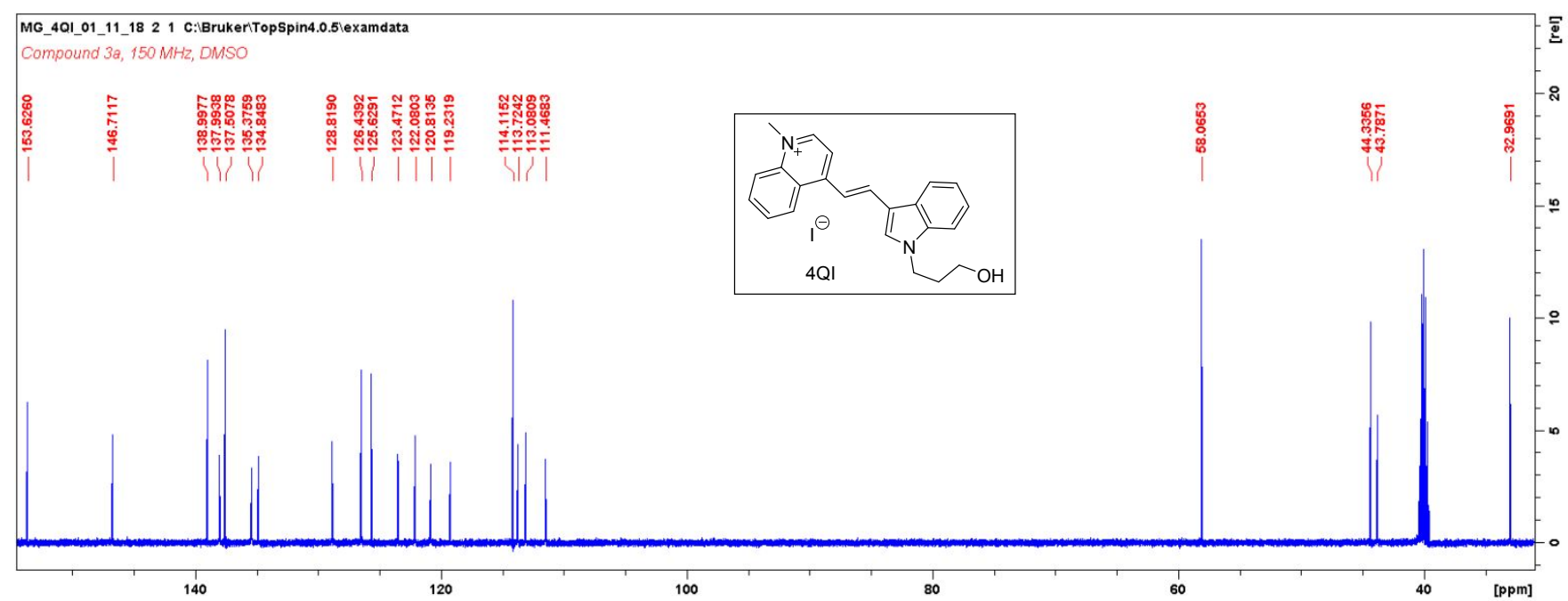

Figure S11. ${ }^{13} \mathrm{C}$-jmod NMR spectra of $4 \mathrm{QI}$. 


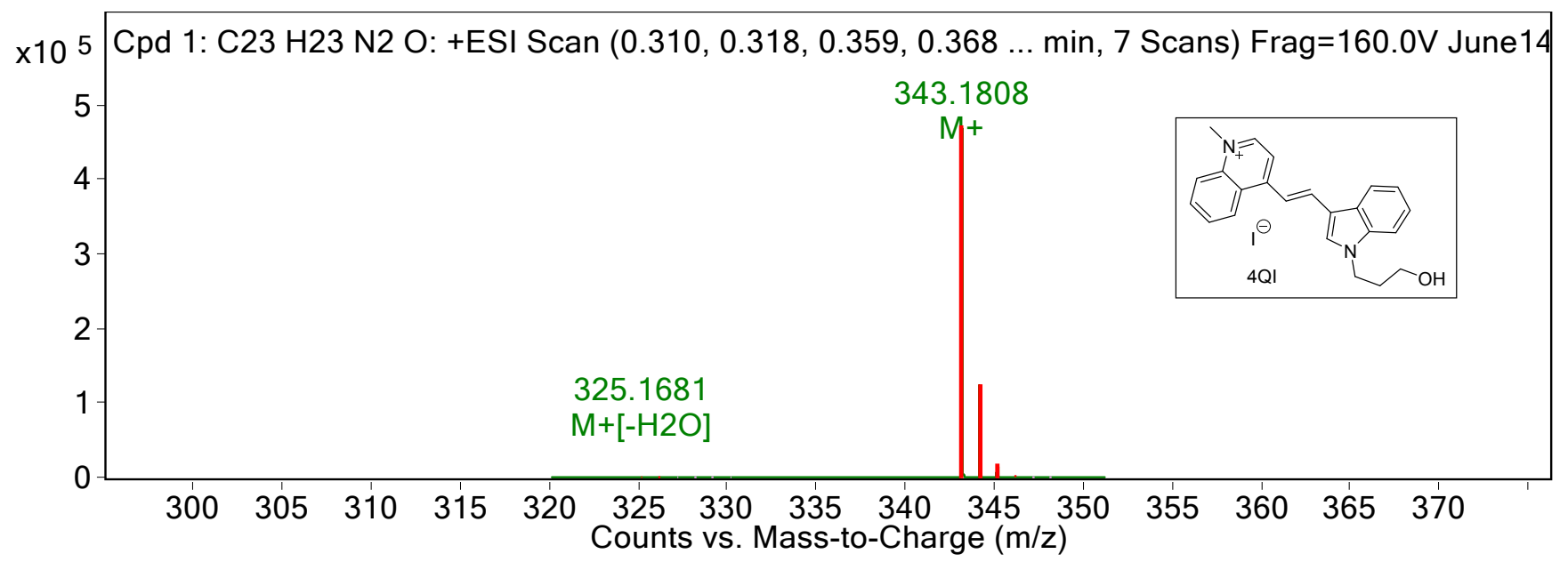

Figure S12. HRMS spectra of 4QI.

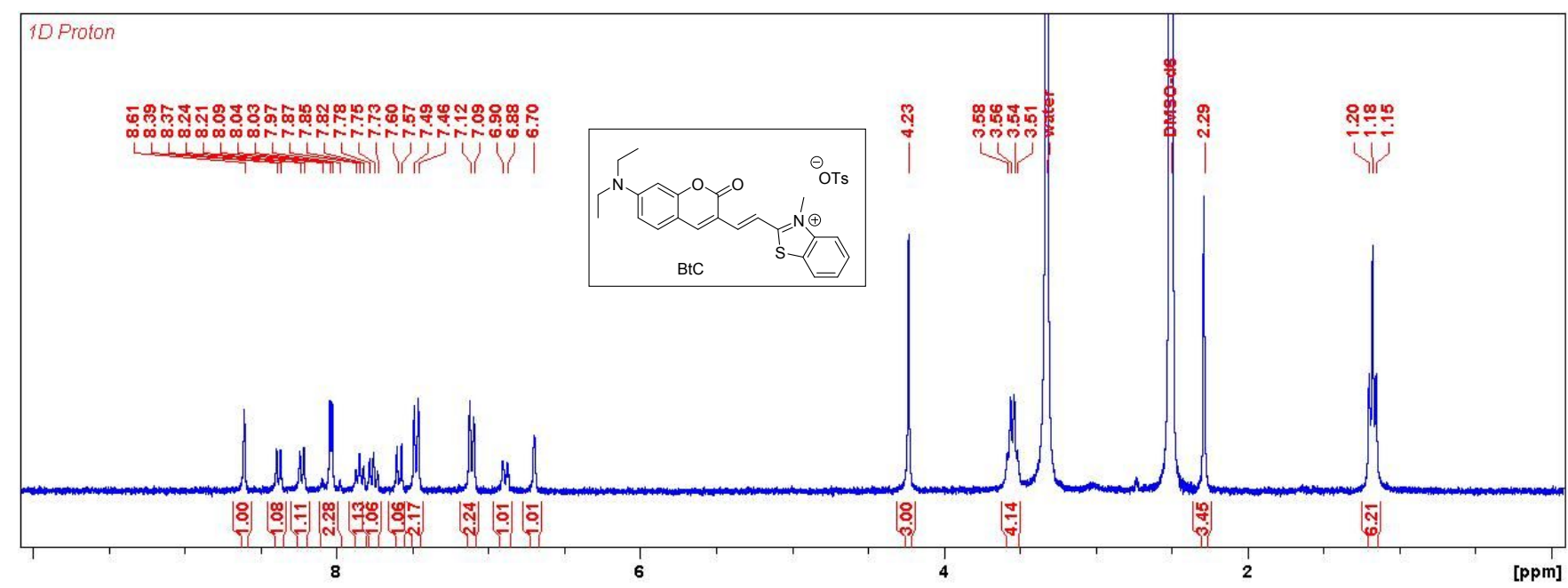

Figure S13. ${ }^{1} \mathrm{H}$ NMR spectra of BtC. 